\title{
Topping Phenomenon with Recurrent Spinal Stenosis and Epidural Fibrosis Prevented with Oxidized Cellulose - a Case Report
}

\author{
Radek Hart*
}

\begin{abstract}
Lumbar spinal stenosis is a condition where the neural structures are compressed in the narrowed spinal canal and often situated only within a single specific segment of the spine, most frequently in the lumbar spine. A case report demonstrates a surgical solution of lumbar spinal stenosis with using oxidized cellulose as a prevention of post-operative adhesions and failed back syndrome. A female patient (68) with a significant pain of the lumbar spine lasting for a number of months due to advanced spondylosis, failing to respond to conservative treatment underwent instrumented, posterolateral fusion of affected segments. The patient re-arrived with pain due to spinal stenosis in another segments after 4 and then after 3 years. We repeatedly performed spinal fusion of the affected segments and applied an antiadhesive gel to the dural sac and the decompressed nerve roots to prevent the development of post-operative adhesions and the "failed back syndrome". Last surgical solution included mobilisation of the simultaneously constricted dural sac through laminectomy. This time we covered the sac using a haemostat made of oxidized cellulose (Traumacel FAM). After this treatment, the patient was again without significant difficulties.
\end{abstract}

\section{KEYWORDS}

spinal stenosis; post-operative adhesion; prevention; oxidized cellulose; Traumacel FAM

\section{AUTHOR AFFILIATIONS}

Department of Orthopaedics and Traumatology, General Hospital Znojmo, Czech Republic

* Corresponding author: Department of Orthopaedics and Traumatology, General Hospital Znojmo, MUDr. Jana Janského 11, 669 02 Znojmo, Czech Republic; e-mail: radek.hart@nemzn.cz

Received: 3 March 2018

Accepted: 17 June 2018

Published online: 14 September 2018

Acta Medica (Hradec Králové) 2018; 61(2): 69-73

https://doi.org/10.14712/18059694.2018.55

(c) 2018 The Author. This is an open-access article distributed under the terms of the Creative Commons Attribution License

(http://creativecommons.org/licenses/by/4.0), which permits unrestricted use, distribution, and reproduction in any medium, provided the original author and source are credited. 


\section{INTRODUCTION}

The pain in the lumbar spine is a very frequent patient complaint seen in consultation rooms of general practitioners and specialists. Lumbar spine disorders hold the second position, after airway diseases, in the frequency of patient visits to first-line physicians and present a high proportion of applications for a disability pension. It is also one of the most frequent causes of incapacity for work because it particularly affects patients of the working age, and with the frequently recurrent pain attacks, the financial cost of treatment of chronic vertebropathy is enormous.

Degenerative diseases of the lumbar spine start to develop in humans often very early - in the second and third decade of life, with intervertebral lumbar discs 4 and 5 being affected most frequently. Often, we observe gradual deterioration in all the segments, typically in the lumbar spine. It is the price paid for walking upright on two legs.

For the lumbar spine, results of treatment are usually not as clear as for the diseases of the majority of other anatomical areas of the locomotor system; they are also accompanied by a higher percentage of complications. The choice of the method of treating the degenerative disease of the lumbar spine still remains controversial. Conservative therapy should always be the method of first choice. It needs to be conducted strictly on an individual basis, in a comprehensive manner, and sufficiently long. Only when it fails, we start considering the eventual indication for the surgery in such a patient. Nowadays, spinal fusion still remains a conventional surgical solution. If correctly indicated, it demonstrably improves the quality of life of patients. To date, no one has demonstrated whether the subsequent degeneration of the adjacent segments ("topping syndrome") is caused by spinal fusion or a natural progression of the degenerative process. When evaluating the overall rate of success, spinal fusion treatment, despite the considerable progress in this field, does not fully achieve the level of effect that we can normally see today following compensation of large joints - particularly those of hip (1).

Lumbar spinal stenosis is a condition where the neural structures are compressed in the narrowed spinal canal. This can be a generalised narrowing and can affect the spine in its entirety or, more often, be situated only within a single specific segment of the spine, which most frequently involves the lumbar spine (2). In terms of etiology, it may be primary - congenital/developmental disease, or, more often, a secondary - acquired disease, which mostly involves a degenerative process. Stenosis of the lumbar spine segment is seen most frequently. It was first described in 1949 by Henk Verbiest (1909-1997), a Dutch neurosurgeon. Depending on the location of the narrowing one can distinguish among (a) spinal stenosis in the strict sense (central stenosis), which affects vertebral foramina / spinal canal as such; (b) lateral (uni-/bilateral) stenosis, which presents the narrowing of lateral recessus; and (c) stenosis of the intervertebral foramen (3).

The increasing quality and availability of imaging lead, along with the growing range of therapeutic alternatives, to spinal stenosis being increasingly diagnosed and treat- ed; gradually, also, it is becoming one of the most frequent indications for surgery of the lumbar spine. Spinal claudication that restricts the walking ability of patients with major central lumbar stenosis who sometimes are able to walk for just a few metres is typical in such individuals. Should comprehensive conservative management in the duration of at least three months not lead to improvements, decompression in the form of (mostly instrumented) laminectomy may provide relief $(4,5)$.

The resulting post-operative scars and their adhesions to the initially relaxed dural sac may be the cause for the development of the so-called "failed back syndrome", i.e., a gradually emerging relapse of patient's difficulties. This is something that we have been striving to prevent by applying an anti-adhesion gel on the dural sac. Its relatively high price of the preparation and, in particular, as well as supply deficits necessitated a search for alternative solutions. As an option, we began to use resorbable haemostats on the basis of oxidised cellulose (Traumacel FAM). Oxidized cellulose is made from pure, natural cotton using controlled oxidation technology. The material with good flexibility is adaptable and has a fibrous structure allowing easy adjustments and can be easily split to obtain the needed quantity. Oxidized cellulose easily adapts to an uneven or poorly accessible surface and in contact with body fluids it turns into a gel and thus minimizes perioperative and early postoperative blood losses and complications. It is atraumatic and $100 \%$ resorbable in the body. The antimicrobial properties against a wide range of microorganism are another advantage of oxidized cellulose. In surgery it is usually used in all areas of stopping diffuse bleeding from resection surfaces of parenchymatous organs muscles or body cavities.

\section{CASE REPORT}

A female patient (68) was referred to our department due to a significant pain of the lumbar spine lasting for a number of months, with no radicular symptomatology, failing to respond to conservative treatment. Advanced spondylosis was found in standard X-ray scan, CT and MRI examinations, affecting L3-L4 and L5-S1 segments. Subsequently, we carried out instrumented, posterolateral fusion of these two segments, and, as a preventative measure, stabilised the healthy L4-L5 segment using a flexible interlaminar implant (Fig. 1). The patient was satisfied after this treatment. Four years later, the pain in her lumbar spine reappeared, this time associated with spinal claudications. Functional X-ray images revealed spondylosis and instability of the L4-L5 segment; MRI images also showed a major central stenosis of this segment. Therefore, spinal fusion was performed for the L4-L5 segment as well - PLIF technique was used which simultaneously releases the dural sac in the segment. An anti-adhesive gel was applied to the dural sac and the decompressed nerve roots to prevent the development of post-operative adhesions and the emergence of "failed back syndrome" (Fig. 2). The still healthy segment L2-L3, was treated with a flexible interlaminar implant to avoid the "topping syndrome". Again, the subjective condition of the patient after 
this intervention was satisfactory. After three years, however, she re-arrived at our outpatient department with pain, this time in the thoracolumbal segment, and newly developed spinal claudications. Standard X-ray and MRI scans revealed a new degeneration of intervertebral discs in the thoracolumbal junction, with the maximum extent present in the L1-L3 segments where a major central stenosis had also developed (Fig. 3). After consultation with the patient, we extended the transpedicular instrumentation with posterolateral fusion up to T10 (to prevent the frequent "topping syndrome" in the region of the thoracolumbal junction), added S2-iliac screws to ensure fourpoint fixation of long instrumentation in the sacral region, and mobilised the simultaneously constricted dural sac through laminectomy of the L1-L3 vertebrae (Fig. 4). We covered the sac to prevent post-operative adhesions and the "failed back syndrome", this time using haemostat made of oxidized cellulose (Traumacel FAM Strata
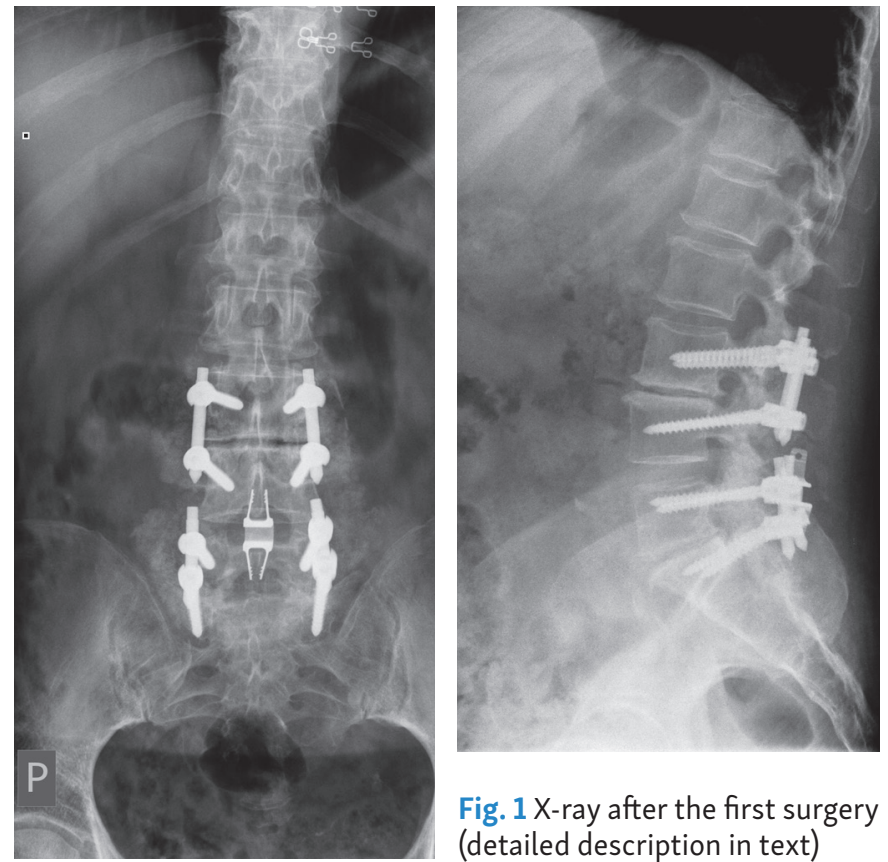

Fig. 1 X-ray after the first surgery (detailed description in text)
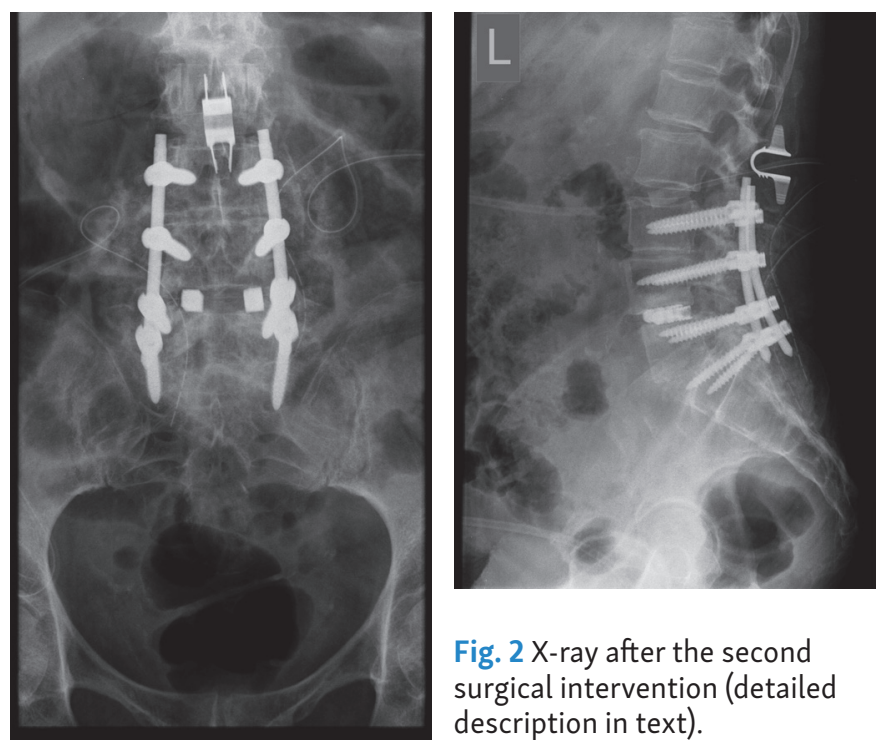

Fig. 2 X-ray after the second surgical intervention (detailed description in text).
$7.5 \times 5 \mathrm{~cm}$ ) (Figs. 5 and 6). After this treatment, the patient is again without significant difficulties. She is now being followed-up for another three years and does not complain of any troubles regarding spinal claudications or nerve root irritation.

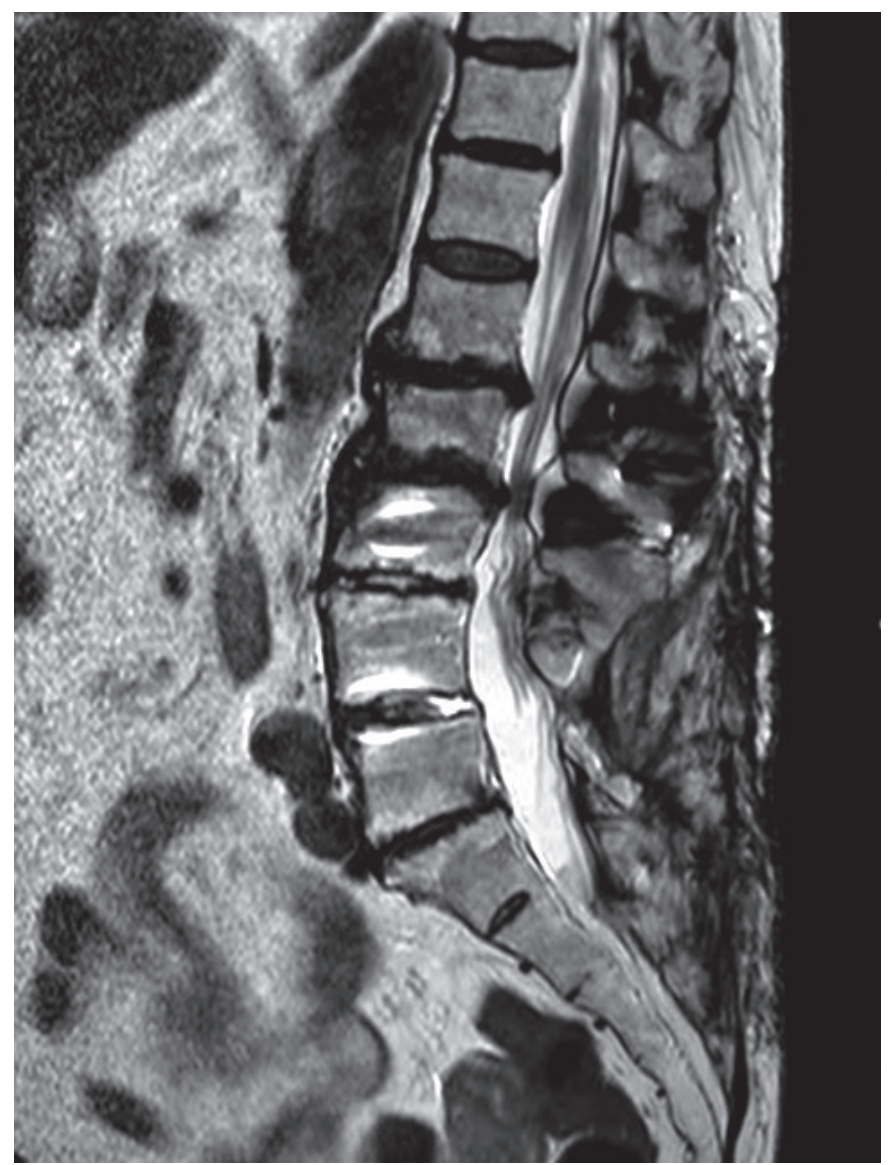

Fig. 3 MRI finding of severe absolute central spinal stenoses L1-L3 before the last surgical intervention.

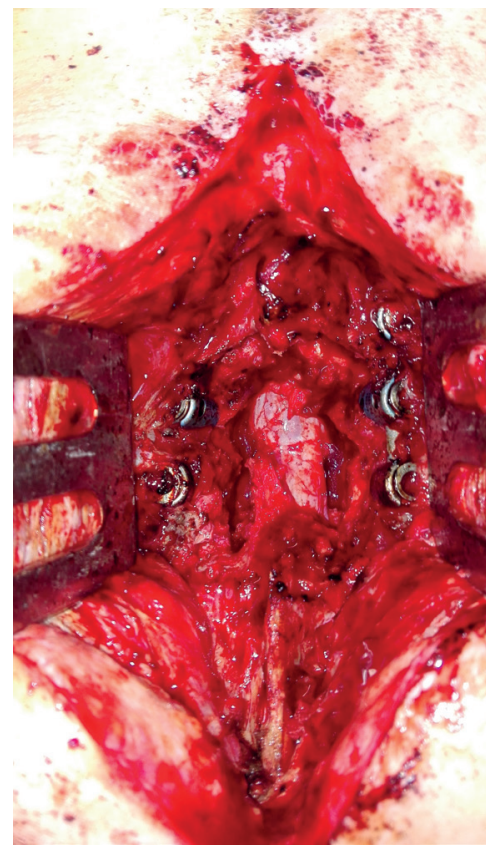

Fig. 4 Decompressed dural sac after laminectomy 


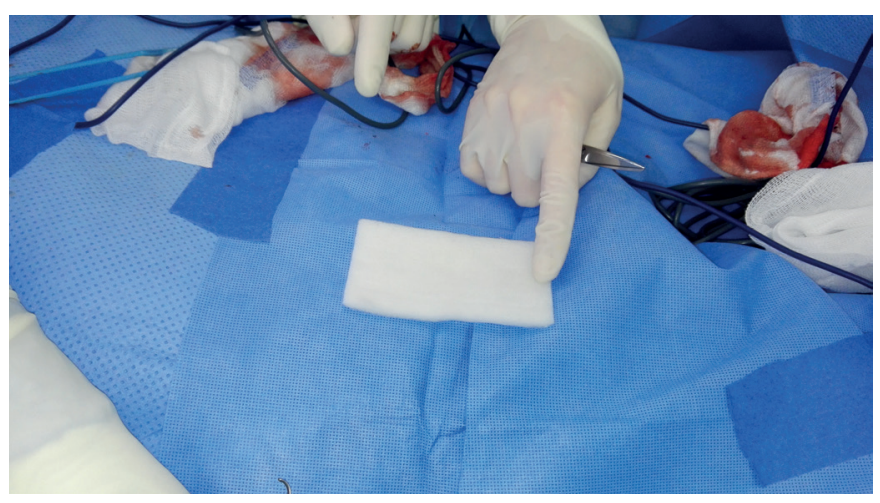

Fig. 5 Oxidized cellulose (Traumacel FAM Strata $7.5 \times 5 \mathrm{~cm}$ ).

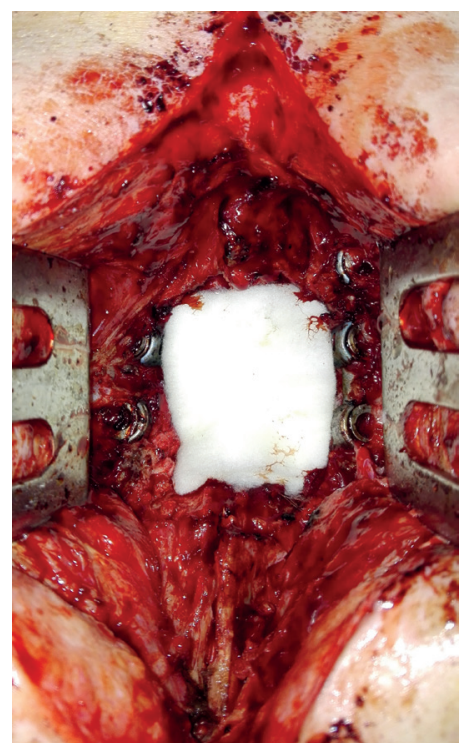

Fig. 6 The cover of the dural sac with a haemostatic agent made of oxidized cellulose Traumacel FAM Strata $7.5 \times 5 \mathrm{~cm}$.

\section{DISCUSSION}

The development of degenerative changes in the lumbar spine is a very frequent problem in the local population, with a high interindividual variability in the degree of subjective complaints. Any occurring concomitant narrowing of the spinal canal aggravites the condition. For a long time, correlation between the morphological changes and the severity of the spinal claudication was not clear. In spinal stenosis, the discrepancy between the dimensions of the nerve structures and the space available in the spinal canal is the key issue. This causes mechanical compression of both nerve and vascular structures and a complex of typical clinical symptoms. In 1954, Verbiest classified lumbar spinal stenosis, based on the anteroposterior diameter of the spinal canal, as the absolute type, dimension $<10 \mathrm{~mm}$, and the relative type, dimension of 10-14 $\mathrm{mm}$. The main problem with quantifying classification is that the severity of the structural finding does not correlate with that of the clinical finding, i.e., that the degree of compression of the nerve structure is not a factor for the severity of the symptoms, thus not any guide to indicate a surgical intervention, i.e., decompression. Crucial in this regard was the paper by Barze et al. (Fig. 6) of 2010. Using the so-called "sedimentation sign" in the magnetic resonance imaging (MRI), they managed to distinguish non-specific low back pain from symptomatic lumbar spinal stenosis. In the same year, Schizas et al. (Fig. 7) quantitatively scaled the severity of lumbar spinal stenosis on the basis of the morphology obtained as part of an MRI examination (T2-weighted) with regard to the indication and the prognosis of surgical decompression of the dural sac. In the mildest lumbar spinal stenosis grade (A), there is "free" space in the dural sac around the nerve roots (a negative sedimentation sign). For grade B, nerve roots evenly fill the entire space of the dural sac; there is no "free" liquor around them (a positive sedimentation sign). For grade A and B, surgical solutions are not recommended - conservative treatment is usually sufficient. For grade $\mathrm{C}$, cerebro-spinal fluid is no longer noticeable on MRI and roots are less differentiable; dorsal epidural fat is however still apparent, and the cross-section of the spinal canal has its typical triangular shape. For the most severe grade, D, the cross-section of the spinal canal is so small that neither nerve roots nor epidural fat can be identified. Patients with C/D grade are no longer appropriate to undergo conservative therapy and shall be indicated for surgical treatment.

The decompression of the nerve structure as such is just the first step of the treatment of the spinal stenosis. The second step involves the effort to prevent post-operative adhesions and the "failed back syndrome". For a number of years, application of an anti-adhesive gel was recommended for this purpose; the special gel has been proven to have a positive effect of preventing adhesions. However, new studies are emerging pointing the risks associated with the use of this gel (8). This fact, combined with interruptions in the supplies of the product, led us to the effort to find a different solution. The discussion on this topic is still very limited in the world literature, and published scientific studies (mostly from Turkey) were conducted only on laboratory animals. Some of these works show a significant positive effect of oxidized cellulose on the prevention of epidural fibrosis $(9,10)$, another a significantly lower effect $(11,12)$.

\section{CONCLUSION}

Our first experience with Traumacel FAM, resorbable haemostat made of oxidised cellulose, as part of preventing dural sac adhesions, is very good. Longer follow-up is necessary to confirm our first results.

\section{REFERENCES}

1. Hart R, et al. Degenerativní onemocnění páteře. Praha: Galén, 2014.

2. Delank KS, Fürderer S, Eysel P. Die lumbale Spinalkanalstenose. Z Orthop 2004; 142: 19-35.

3. Schulte TL, Bullmann V, Lerner T, et al. Lumbale Spinalkanalstenose. Orthopäde 2006; 35: 675-94.

4. Yuan PS, Albert TJ. Nonsurgical and surgical management of lumbar spinal stenosis. J Bone Joint Surg Am 2004; 86: 2320-30.

5. Hansraj KK, Cammisa FP, O'Leary PF. Decompressive surgery for typical lumbar spinal stenosis. Clin Orthop 2001; 384: 10-17. 
6. Barz T, Melloh M, Staub LP et al. Nerve root sedimentation sign. Evaluation of a new radiological sign in lumbar spinal stenosis. Spine 2010; 35: 892-7.

7. Schizas C, Theumann N, Burn A, et al. Qualitative grading of severity of lumbar spinal stenosis based on the morphology of the dural sac on magnetic resonance images. Spine 2010; 35: 1919-24.

8. Kim SB, Lim YJ. Delayed detected unexpected complication of Adcon-L Gel in lumbar surgery. J Korean Neurosurg Soc 2010; 48: 268-71.

9. Temel SG, Ozturk C, Temiz A, et al. A new material for prevention of epidural fibrosis after laminectomy: oxidized regenerated cellulose (interceed), an absorbable barrier. J Spinal Disord Tech 2006; 19: $270-5$.
10. Rodgers KE, Robertson JT, Espinosa T, et al. Reduction of epidural fibrosis in lumbar surgery with Oxiplex adhesion barriers of carboxymethylcellulose and polyethylene oxide. Spine J 2003; 3: 277-83.

11. Altun I. An experimental study of histopathologic effects of hemo static agents used in spinal surgery. World Neurosurg 2016; 90 : 147-53.

12. Karasu H, Güzel I. Comparison TachoComb with SurgiWrap, Surgicel and Lyodura in epidural fibrosis: an experimental rat model. Ideggyogy Sz 2016; 30: 195-200. 